\title{
配電系統用SVCの安定性評価に関する検討
}

\author{
正員 清水 慶一* 正員 元治 崇* \\ 正 員 中沢 親志** 正 員 中西 要祐**
}

\section{Stability Estimation of SVCs in Distribution Systems}

Keiichi Shimizu*, Member, Takamu Genji*, Member, Chikashi Nakazawa**, Member, Yosuke Nakanishi**, Member

This paper presents stability and an interactive phenomenon of one SVC, two or more sets of SVC, a SVC and a SVR in distribution systems. In particular, we focus on the saddle-node bifurcation and Hopf bifurcation points. The two local bifurcation points show a boundary of a stable domain.

キーワード：配電系統，無効電力補償装置，電圧調整器，分岐

Keywords: distribution system, static var compensator (SVC), step voltage regulator (SVR), bifurcation

\section{1. まえがき}

これまで配電系統の電圧制御はあらかじめ把握した系統 データをもとにお客さま側の電圧を予測する方式により運 用されている。しかし, 分散電源, 特に風力発電・太陽光 発電など, 発電量に比較的大きな変動要素が含まれる場合, 弚れらの導入により，従来方式による電圧管理は困難とな る。これらの問題を解決するため，高速かつ連続制御が可 能なSVC など , パワエレ機器の配電系統への導入が進め られている。上位系統においては複数台 SVC の相互干渉 による不安定性が報告されており (1)(2)，配電系統において も SVC 導入に関して，今後これら相互干渉を回避できる 制御・整定方法, 設置位置といった制約条件を整理する必 要がある。本論文では, 上述した項目の基礎検討として配 電系統における単機 SVC , 2 機 SVC の不安定現象，SVC とSVR の相互干渉問題を検討し，特にSVC を含む系統の サドル・ノード分岐点とホップ分岐点 (局所分岐) に注目 し SVCが安定に動作できる領域を明確化した。

2. 定式化と実効值モデル

〈2 1〉 単機 SVC を含む系統＼cjkstart文献(1), (2) で検討さ

*関西電力 (株) 電力技術研究所 電力基盤技術研究室 (流通) T 661-0974 尼崎市若王寺 3-11-20

Kansai Electric Power Co., Inc. Power Engineering R\&D Center 3-11-20, Nakouji, Amagasaki 661-0974

**富士電機アドバンストテクノロジー (株) 情報通信制御部 最適化 システム $\mathrm{Gr}$

テ 191-8502 日野市富士町 1 番地

Fuji Electric Advanced Technology Co., Ltd. Information and Control Department, Optimization Systems Gr.

1, Fuji-machi, Hino 191-8502
れた系統を参考にSVC を含む配電系統の定式化および解 析用実効値モデルの導出を行う。検討した系統を図 1 に示 す。無限大母線 $\dot{V}_{\text {inf }}$ に配電線を介して SVC が接続されて いる。 $r_{e}+j X_{e}, I_{e}, G-j B, \dot{I}_{L}, \dot{V}_{S V C}, \dot{I}_{S V C}$ は光れ光れ 配電線のインピーダンス, 電流, 負荷のアドミタンス, 電 流, SVC の電圧, 電流を表す。負荷は定インピーダンスモ デルとして表現した。変数上のドット $(\cdot)$ は複素数を表す。 SVC はリアクトルを表現したサセプタンス $B_{L}$ を制御する TCR 型とする。SVC は AVR により電圧一定制御を行い， SVC の電圧，電流の大きさ $V_{S V C}, I_{S V C}$ により決まるサセ プタンス值をとるモデルとする (SVC のコンデンサを表現 したサセプタンス $B_{C}$ は固定とする)。各電流は矢印方向を 正とする。制御系を除く系統方程式を定式化すると (1) (4) 式となる。

$$
\begin{aligned}
& -\dot{I}_{S V C}=j\left(B_{C}-B_{L}\right) \dot{V}_{S V C} \\
& \dot{V}_{\text {inf }}-\dot{V}_{S V C}=\left(r_{e}+j X_{e}\right) \dot{I}_{e} \\
& \dot{I}_{L}=(G-j B) \dot{V}_{S V C} \cdots \cdots \\
& \dot{I}_{L}=\dot{I}_{e}+\dot{I}_{S V C} \ldots \ldots \ldots \ldots
\end{aligned}
$$

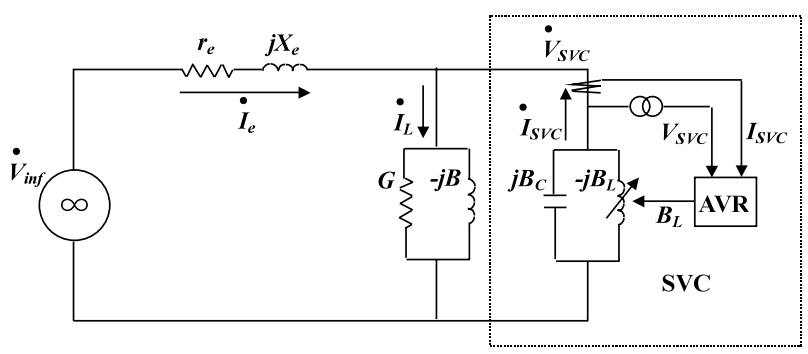

图 1 単機 SVC の系統モデル

Fig. 1. A system model with a SVC. 
また制御系 (AVR) を図 2 に示す。(1)〜(4) 式より $\dot{V}_{S V C}$ を表すと (5) 式となる。

$$
\dot{V}_{S V C}=\frac{\dot{V}_{\text {inf }}}{1+\left(r_{e}+j X_{e}\right)\left\{G+j\left(B_{C}-B_{L}-B\right)\right\}} .
$$

ここで $S V C$ 電圧 $\dot{V}_{S V C}$ の大きさ $V_{S V C}$ は (6) 式となる。

$$
=\frac{V_{S V C}}{\sqrt{\left\{1+r_{e} G-X_{e}\left(B_{C}-B_{L}-B\right)\right\}^{2}+\left\{X_{e} G+r_{e}\left(B_{C}-B_{L}-B\right)\right\}^{2}}}
$$

さらに (6) 式の右辺をまとめると (7) 式となる。

$$
V_{S V C}=\frac{V_{\text {inf }}}{\sqrt{a_{2} B_{L}^{2}+a_{1} B_{L}+a_{0}}}
$$

ここで，

$$
\begin{aligned}
a_{0}= & 1+\left(r_{e}^{2}+X_{e}^{2}\right)\left\{G^{2}+\left(B_{C}-B\right)^{2}\right\} \\
& +2\left\{r_{e} G-X_{e}\left(B_{C}-B\right)\right\} \\
a_{1}= & 2\left\{X_{e}-\left(r_{e}^{2}+X_{e}^{2}\right)\left(B_{C}-B\right)\right\} \\
a_{2}= & r_{e}^{2}+X_{e}^{2}
\end{aligned}
$$

また (1) 式より SVC 電流 $I_{S V C}$ の大きさ $I_{S V C}$ は (8) 式と なる。

$$
I_{S V C}=\left(B_{C}-B_{L}\right) V_{S V C}
$$

次にAVR を微分方程式で表現する。AVR は图 2 に示し たモデルとする。図 2 を微分方程式で表現すると (9) 式と なる。

$$
\left.\begin{array}{l}
T_{m} \frac{d x}{d t}=-x+V_{S V C}+k I_{S V C} \\
T_{n} \frac{d y}{d t}=-x+V_{S V C r e f} \\
T_{T} \frac{d B_{L}}{d t}=k_{0} k_{p} x-k_{0} k_{p} y-B_{L}-k_{0} k_{p} V_{S V C r e f}
\end{array}\right\}
$$

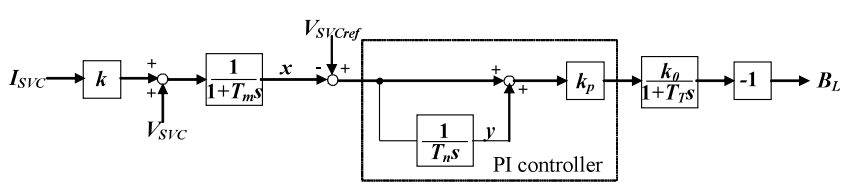

图 $2 \mathrm{SVC}$ の制御系 (AVR)
(7)，(8) 式を (9) 式に代入し， $V_{S V C}, I_{S V C}$ を消去すると (10) 式となる。

$$
\begin{aligned}
& T_{m} \frac{d x}{d t}=-x+\left\{-k B_{L}+\left(1+k B_{C}\right)\right\} V_{\text {inf }} \mid \\
& \sqrt{a_{2} B_{L}^{2}+a_{1} B_{L}+a_{0}} \\
& T_{n} \frac{d y}{d t}=-x+V_{S V C r e f} \\
& \left.T_{T} \frac{d B_{L}}{d t}=k_{0} k_{p} x-k_{0} k_{p} y-B_{L}-k_{0} k_{p} V_{S V C r e f}\right)
\end{aligned}
$$

ここで初期值は以下とする。

$$
\left(\begin{array}{c}
x \\
y \\
B_{L}
\end{array}\right)_{t=0}=\left(\begin{array}{c}
x_{0} \\
y_{0} \\
B_{L 0}
\end{array}\right)
$$

(10) 式は状態変数 $x, y, B_{L}$, パラメータ変数 $T_{m}, T_{n}, T_{T}$, $k, k_{0}, k_{p}, V_{S V C r e f}, V_{\text {inf }}, r_{e}, X_{e}, G, B, B_{C}$ の 3 次の非 線形微分方程式である。(10) 式を単機 SVC の実効值モデ ルと呼ぶこととする。

〈2. 2〉2 機 SVCを含む系統検討した系統を图 3 に 示す。制御系を除く系統方程式を定式化すると (11) 式とな る。ここで(11)式のドット (・) は複素数を表す。

$$
\left.\begin{array}{l}
-\dot{I}_{S V C 1}=j\left(B_{C 1}-B_{L 1}\right) \dot{V}_{S V C 1} \\
-\dot{I}_{S V C 2}=j\left(B_{C 2}-B_{L 2}\right) \dot{V}_{S V C 2} \\
\dot{V}_{i n f}-\dot{V}_{S V C 1}=\left(r_{e 1}+j X_{e 1}\right) \dot{I}_{e 1} \\
\dot{V}_{S V C 1}-\dot{V}_{S V C 2}=\left(r_{e 2}+j X_{e 2}\right) \dot{I}_{e 2} \\
\dot{I}_{L 1}=\left(G_{1}-j B_{1}\right) \dot{V}_{S V C 1}, \dot{I}_{L 2}=\left(G_{2}-j B_{2}\right) \dot{V}_{S V C 2} \\
\dot{I}_{S V C 1}=\dot{I}_{e 2}+\dot{I}_{L 1}-\dot{I}_{e 1}, \dot{I}_{S V C 2}=\dot{I}_{L 2}-\dot{I}_{e 2}
\end{array}\right\}
$$

また制御系 (AVR) は図 2 の制御系を用いた。単機 SVC の場合と同樣に，SVC 電圧と SVC 電流の大きさ $V_{S V C 1}$, $V_{S V C 2}, I_{S V C 1}, I_{S V C 2}$ を求め，二れを図 2 を表現する式に代 入すると (12) 式を得る。

Fig. 2. A controller of the SVC (AVR).

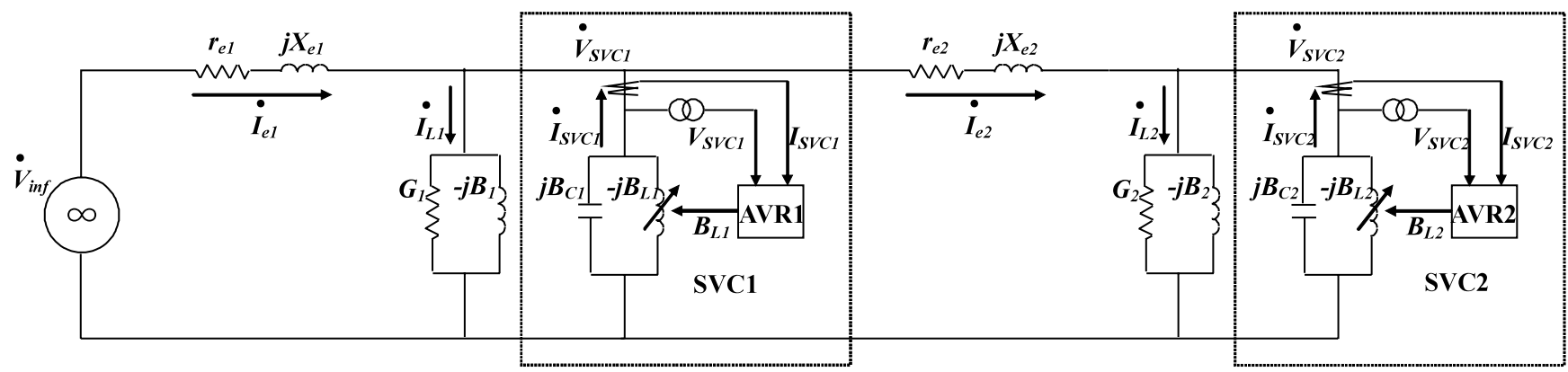

図 32 機 SVC の系統モデル

Fig. 3. A system model with two SVCs. 


$$
\begin{aligned}
T_{m 1} \frac{d x_{1}}{d t}= & -x_{1}+\left\{-k_{1} B_{L 1}+\left(1+k_{1}+B_{C 1}\right)\right\} \\
& \times \sqrt{\beta / \alpha} V_{\text {inf }} \\
T_{n 1} \frac{d y_{1}}{d t}= & -x_{1}+V_{S V C r e f 1} \\
T_{T 1} \frac{d B_{L 1}}{d t}= & k_{p 1} k_{01} x_{1}-k_{p 1} k_{01} y_{1}-B_{L 1} \\
& -k_{p 1} k_{01} V_{S V C r e f 1} \\
T_{m 2} \frac{d x_{2}}{d t}= & -x_{2}+\left\{-k_{2} B_{L 2}+\left(1+k_{2} B_{C 2}\right)\right\} \sqrt{c_{00} / \alpha} V_{\text {inf }} \\
T_{n 2} \frac{d y_{2}}{d t}= & -x_{2}+V_{S V C r e f} \\
T_{T 2} \frac{d B_{L 2}}{d t}= & k_{p 2} k_{02} x_{2}-k_{p 2} k_{02} y_{2}-B_{L 2} \\
& -k_{p 2} k_{02} V_{S V C r e f 2}
\end{aligned}
$$

ここで，

$$
\begin{aligned}
\alpha= & a_{00}+a_{10} B_{L 1}+a_{01} B_{L 2}+a_{11} B_{L 1} B_{L 2}+a_{21} B_{L 1}^{2} B_{L 2} \\
& +a_{12} B_{L 1} B_{L 2}^{2}+a_{20} B_{L 1}^{2}+a_{02} B_{L 2}^{2}+a_{22} B_{L 1}^{2} B_{L 2}^{2} \\
\beta= & b_{00}+b_{01} B_{L 2}+b_{02} B_{L 2}^{2}
\end{aligned}
$$

$a_{00}, b_{00}, c_{00}$ 等は系統のインピーダンス，制御系の定数で 決定される值。

(12) 式は状態変数 $x_{1}, y_{1}, B_{L 1}, x_{2}, y_{2}, B_{L 2}$, パラメー 夕変数 $T_{m 1}, T_{n 1}, T_{T 1}, k_{1}, k_{01}, k_{p 1}, V_{S V C r e f 1}, r_{e 1}, X_{e 1}$ ， $G_{1}, B_{1}, B_{C 1}, T_{m 2}, T_{n 2}, T_{T 2}, k_{2}, k_{02}, k_{p 2}, V_{S V C r e f 2}, r_{e 2}$, $X_{e 2}, G_{2}, B_{2}, B_{C 2}, V_{\text {inf }}$ の 6 次非線形微分方程式である。 (12) 式を 2 機 SVC の実効值モデルと呼ぶこととする。

〈2 3〉SVCとSVRを含む系統検討した系統を図 4， 系統方程式を (13) 式に示す。式中のドット $(\cdot)$ は複素数を 表す。

$$
\left.\begin{array}{l}
-\dot{I}_{S V C}=j\left(B_{C}-B_{L}\right) \dot{V}_{S V C} \\
\dot{V}_{i n f}-\dot{V}_{S V R 1}=\left(r_{e 1}+j X_{e 1}\right) \dot{I}_{e 1} \\
\dot{V}_{S V R 2}-\dot{V}_{S V C}=\left(r_{e 2}+j X_{e 2}\right) \dot{I}_{e 2} \\
\dot{I}_{L 1}=\left(G_{1}-j B_{1}\right) \dot{V}_{S V R 2} \\
\dot{I}_{L 2}=\left(G_{2}-j B_{2}\right) \dot{V}_{S V C} \\
\dot{I}_{L 2}=\dot{I}_{e 2}+\dot{I}_{S V C} \\
\dot{I}_{L 1}+\dot{I}_{e 2}=\dot{I}_{e 1}^{\prime}, \dot{I}_{e 1}^{\prime} / \dot{I}_{e 1}=1 / n \\
\dot{V}_{S V R 2} / \dot{V}_{S V R 1}=n
\end{array}\right\}
$$

これまでと同樣にSVC の制御系は図 2 の制御系を用い た。SVR の制御方程式 (3)(4) を(14) 式に示す。 $n, V_{S V R r e f}$ ， $T_{S}$ は矢れ光れ SVR の巻数比, 電圧設定值, 時定数 (ここ では動作遅延時間) を表す。

$$
T_{S} \frac{d n}{d t}=-V_{S V R 2}+V_{S V R r e f}
$$

単機 SVC , 2 機 SVC の場合と同樣に，(13) 式の SVC， $S V R$ の電圧，電流の大きさ $V_{S V C}, I_{S V C}, V_{S V R}$ を求め，これ を図 2 を表現する式と (14) 式に代入すると (15) 式を得る。

$$
\left.\begin{array}{l}
T_{m} \frac{d x}{d t}=-x+\left\{\left(1+k B_{C}\right) n-k n B_{L}\right\} V_{\text {inf }} / \sqrt{\gamma} \\
T_{n} \frac{d y}{d t}=-x+V_{S V C r e f} \\
T_{T} \frac{d B_{L}}{d t}=k_{0} k_{p} x-k_{0} k_{p} y-B_{L}-k_{0} k_{p} V_{S V C r e f} \\
T_{S} \frac{d n}{d t}=-n \sqrt{g_{00}+g_{01} B_{L}+g_{02} B_{L}^{2}} V_{\text {inf }} / \sqrt{\gamma}+V_{S \text { VRref }}
\end{array}\right\}
$$

$f_{00}, g_{00}$ 等は系統のインピーダンス, 制御系の定数で決定 される值。

(15) 式は状態変数 $x, y, B_{L}, \boldsymbol{n}$, パラメータ変数 $T_{m}, T_{n}$, $T_{T}, k, k_{0}, k_{p}, V_{S V C r e f}, r_{e 1}, X_{e 1}, G_{1}, B_{1}, B_{C}, T_{S}, V_{S V R r e f}$, $r_{e 2}, X_{e 2}, G_{2}, B_{2}, V_{i n f}$ の 4 次非線形微分方程式である。(15) 式を SVC , SVR の実効值モデルと呼ぶこととする。

\section{3. 線形化と固有值モデル}

この章では，前章で求めた実効値モデルを用いて，平衡 点を導出し，光の平衡点近傍での線形化を行うことにより， 固有值モデルを求める。

〈3. 1〉 単機 SVCを含む系統

(1) 平衡点の導出 状態変数の変化量が零となると いう平衡点の定義 ${ }^{(5)}$ より実効值モデル (10) 式の左辺を零と し，2つの平衡点 1 および $2\left(x^{*}, y^{*}, B_{L}^{*}\right)$ を求めると以下と なる。

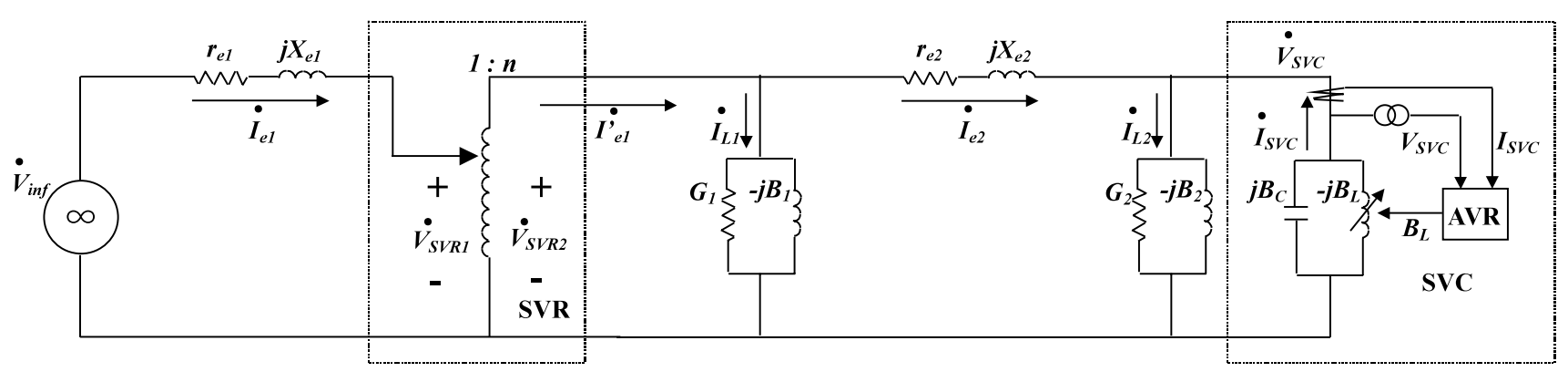

図 4 SVC , SVR を含む系統モデル

Fig. 4. A system model with a SVC and a SVR. 


$$
\begin{aligned}
& x^{*}=V_{S V C r e f}, y^{*}=-B_{L}^{*} /\left(k_{0} k_{p}\right), \\
& B_{L}^{*}=\left(-A_{1} \pm \sqrt{A_{1}^{2}-4 A_{0} A_{2}}\right) /\left(2 A_{2}\right)
\end{aligned}
$$

ここで，

$$
\begin{aligned}
& A_{1}^{2}-4 A_{0} A_{2}>0, A_{0}=a_{0}-\left(1+k B_{C}\right)^{2} V_{\text {inf }}^{2} / V_{\text {SVCref }}^{2} \\
& A_{1}=a_{1}+2 k\left(1+k B_{C}\right) V_{\text {inf }}^{2} / V_{S V C r e f}^{2}, \\
& A_{2}=a_{2}-k^{2} V_{\text {inf }}^{2} / V_{S V C r e f}^{2}
\end{aligned}
$$

（2）線形化 平衡点の存在条件 $\left(A_{1}^{2}-4 A_{0} A_{2}>0\right)$ の もと，実効值モデル (10) 式の平衡点近傍での線形化を行う。 これを(16) 式に示す。

$$
\left(\begin{array}{c}
\Delta \frac{d x}{d t} \\
\Delta \frac{d y}{d t} \\
\Delta \frac{d B_{L}}{d t}
\end{array}\right)=\left(\begin{array}{ccc}
-1 / T_{m} & 0 & f_{B L} / T_{m} \\
-1 / T_{n} & 0 & 0 \\
k_{0} k_{p} / T_{T} & -k_{0} k_{p} / T_{T} & -1 / T_{T}
\end{array}\right)\left(\begin{array}{c}
\Delta x \\
\Delta y \\
\Delta B_{L}
\end{array}\right)
$$

ここで，

$$
\begin{aligned}
f_{B L}= & -\frac{\left\{k a_{1}+2\left(1+k B_{C}\right) a_{2}\right\} B_{L}^{*}+\left\{2 k a_{0}+a_{1}\left(1+k B_{C}\right)\right\}}{2\left(a_{2} B_{L}^{* 2}+a_{1} B_{L}^{*}+a_{0}\right)^{3 / 2}} \\
& \times V_{\text {inf }}
\end{aligned}
$$

(16) 式は状態変数 $\Delta x, \Delta y, \Delta B_{L}$ の 3 次線形微分方程式で ある (パラメータ変数は実効值モデルと同じ)。これを単機 SVC の固有值モデルと呼ぶこととする。

〈3. 2〉 2 機 SVC を含む系統 $\langle 3 \cdot 1\rangle$ 節と同樣に, 2 機 SVC を含む系統についても, 平衡点を導出し, 平衡点存在 条件のもと，実効値モデル (12) の平衡点近傍での線形化を 行う。これを(17)式に示す。

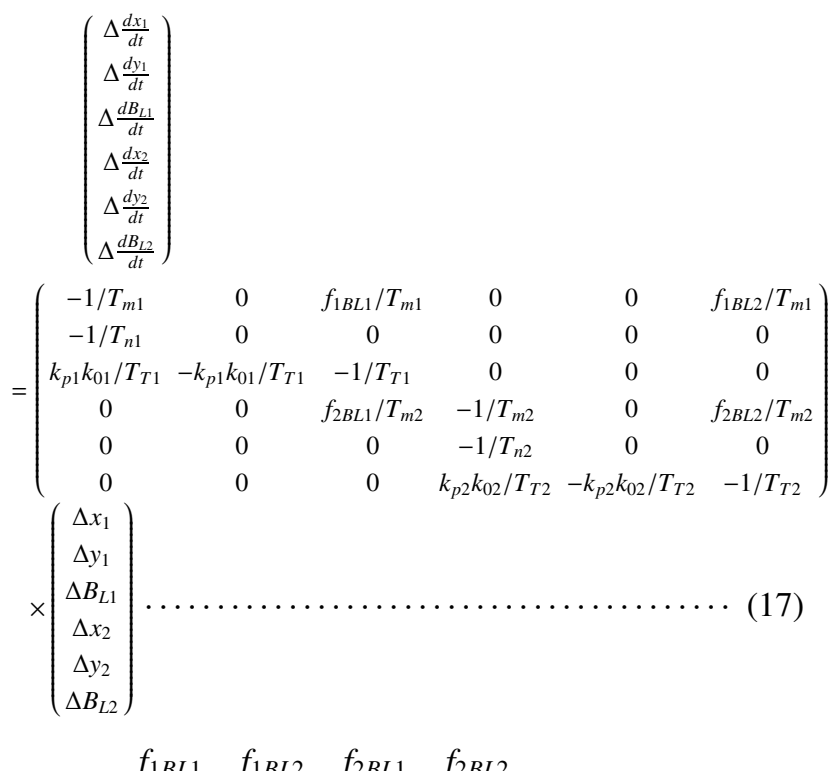

(17) 式は状態変数 $\Delta x_{1}, \Delta y_{1}, \Delta B_{L 1}, \Delta x_{2}, \Delta y_{2}, \Delta B_{L 2}$ の 6 次線形微分方程式である (パラメータ変数は実効值モデ ルと同じ）。これを 2 機 SVC の固有値モデルと呼ぶことと する。
〈3. 3〉SVCと SVRを含む系統

$\langle 3 \cdot 1\rangle$ 節と同樣に， SVC とSVR を含む系統についても，平衡点を導出し，平 衡点存在条件のもと, 実効值モデル (15) 式の平衡点近傍で の線形化を行う。これを(18) 式に示す。

$$
\begin{aligned}
\left(\begin{array}{c}
\Delta \frac{d x}{d t} \\
\Delta \frac{d y}{d t} \\
\Delta \frac{d B_{L}}{d t} \\
\Delta \frac{d n}{d t}
\end{array}\right) & =\left(\begin{array}{cccc}
-1 / T_{m} & 0 & f_{1 B L} / T_{m} & f_{1 n} / T_{m} \\
-1 / T_{n} & 0 & 0 & 0 \\
k_{0} k_{p} / T_{T} & -k_{0} k_{p} / T_{T} & -1 / T_{T} & 0 \\
0 & 0 & f_{2 B L} / T_{S} & f_{2 n} / T_{S}
\end{array}\right) \\
& \times\left(\begin{array}{c}
\Delta x \\
\Delta y \\
\Delta B_{L} \\
\Delta n
\end{array}\right) \ldots \ldots \ldots \ldots \ldots \ldots \ldots \ldots \ldots \ldots \ldots
\end{aligned}
$$

ここで, $f_{1 B L}, f_{1 n}, f_{2 B L}, f_{2 n}$ は線形化点での係数。

(18) 式は状態変数 $\Delta x, \Delta y, \Delta B_{L}, \Delta n$ の 4 次線形微分方 程式である (パラメータ変数は実効值モデルと同じ)。これ を SVC,SVR の固有值モデルと呼ぶこととする。

\section{4. 具体的な数值による安定性の検討}

本章では, 単機 $\mathrm{SVC} \cdot 2$ 機 $\mathrm{SVC} \cdot \mathrm{SVC}$ と SVR を含む光

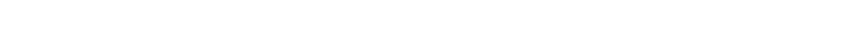
のみを変化させ，弚の変化に対する固有値軌跡の計算を， 固有值モデルを用いて実施し, 安定限界点である分岐点を 求めた。さらに, 分岐点前後のパラメータ值において, 実 効值モデルによる時間軸シミュレーションを実施し，SVC 電圧等が不安定となる樣子を確認した。なお，光れ光れの 標準定数の基準値は $10 \mathrm{MVA}, 6600 \mathrm{~V}, 60 \mathrm{~Hz}$ である。

〈4: 1〉 単機SVCを含む系統 表 1 の定数を標準定数 として検討を行った。AVR の PI 制御後のゲイン $k_{0}=1.0$ とする。配電線亘長はリアクタンス換算で約 $7.78 \mathrm{~km}$ に相 当する。

前章の検討より実効値モデル (10) 式は分岐の発生に関し て, 次の 3 つの条件が存在する。

条件 1: $A_{1}^{2}-4 A_{0} A_{2}>0 \rightarrow 2$ つの平衡点が存在。

条件 $2: A_{1}^{2}-4 A_{0} A_{2}=0 \rightarrow$ サドル・ノード分岐点（限 界点)。

条件 $3: A_{1}^{2}-4 A_{0} A_{2}<0 \rightarrow$ 平衡点なし。

\section{表 1 各パラメータの標準值}

Table 1. The standard values of the each parameter.

\begin{tabular}{|c|c|}
\hline Parameter & Standard value \\
\hline Infinite bus voltage $V_{\text {inf }}$ & $1.0 \mathrm{pu}$ \\
\hline Distribution line resistance $r_{e}$ & $0.4071 \mathrm{pu}$ \\
\hline Distribution line reactance $X_{e}$ & $0.6826 \mathrm{pu}$ \\
\hline Load conductance $G$ & $0.364 \mathrm{pu}$ \\
\hline Load susceptance $B$ & $-0.072 \mathrm{pu}$ \\
\hline Voltage set value of SVC $V_{S V C r e f}$ & $1.0 \mathrm{pu}$ \\
\hline Susceptance of SVC $B_{C}$ & $0.2 \mathrm{pu}$ \\
\hline Slope reactance of SVC $k$ & $0.01 \mathrm{pu}$ \\
\hline PI-controller gain at AVR $k_{p}$ & 2.1 \\
\hline $\begin{array}{c}\text { Time-lag of first order time constant } \\
\text { of voltage measurement at AVR } T_{m}\end{array}$ & $0.03 \mathrm{sec}$ \\
\hline PI-controller time constant at AVR $T_{n}$ & $0.01 \mathrm{sec}$ \\
\hline Time constant after PI-control at \\
AVR $T_{T}$
\end{tabular}


したがって平衡点近傍の局所的な安定性に注目すれば， サドル・ノード分岐点が SVC の安定限界点となる。表 2 に (10)，(16) 式により確認されたサドル・ノード分岐点が 生じるパラメータ值を示す。表 2 を見ると, 配電線の亘長 を除いては，例えば無限大母線電圧が $0.7934 \mathrm{pu}(5236 \mathrm{~V})$ より低い場合であるなど，現実的ではない值となっており， 実運用上は問題ないと考える。

表 2 の結果を考慮し , 固有値モデル (16) 式によりパラ メータ変化に対する固有値軌跡の計算を行った。一例とし て系統負荷コンダクタンス $G$ をパラメータとした場合のサ ドル・ノード分岐点近傍の固有值軌跡を図 5(a) に示す。 $G$

表 2 各パラメータのサドル・ノード分岐点

Table 2. The saddle node bifurcation points of the each parameter.

\begin{tabular}{|c|c|c|}
\hline Parameter & $\begin{array}{c}\text { Bifurcation } \\
\text { point }\end{array}$ & Unstable domain \\
\hline Load conductance $G$ & $0.6266 \mathrm{pu}$ & $0.6266 \mathrm{pu}<G$ \\
\hline $\begin{array}{c}\text { Distribution line resis- } \\
\text { tance } r_{e}\end{array}$ & $0.6193 \mathrm{pu}$ & $0.6193 \mathrm{pu}<r_{e}$ \\
\hline $\begin{array}{c}\text { Distribution line reac- } \\
\text { tance } X_{e}\end{array}$ & $\begin{array}{c}0.2704 \mathrm{pu} \\
2.2262 \mathrm{pu}\end{array}$ & $0.2704 \mathrm{pu}<X_{e}$ \\
\hline $\begin{array}{c}\text { Length of distribution } \\
\text { line } m I t\end{array}$ & $\begin{array}{c}1.7056 \\
\text { times }\end{array}$ & 1.7056 times $<\mathrm{pu} l t$ \\
\hline $\begin{array}{c}\text { Infinite bus voltage } \\
V_{\text {inf }}\end{array}$ & $0.7934 \mathrm{pu}$ & $V_{\text {inf }}<0.7934 \mathrm{pu}$ \\
\hline $\begin{array}{c}\text { Voltage set value of } \\
\text { SVC } V_{S V C r e f}\end{array}$ & $1.2603 \mathrm{pu}$ & $1.2603 \mathrm{pu}<V_{S V C r e f}$ \\
\hline
\end{tabular}

$m l t$ は標準配電線インピーダンス $(0.4071 \mathrm{pu}+\mathrm{j} 0.6826 \mathrm{pu})$ からの倍 率を表す。

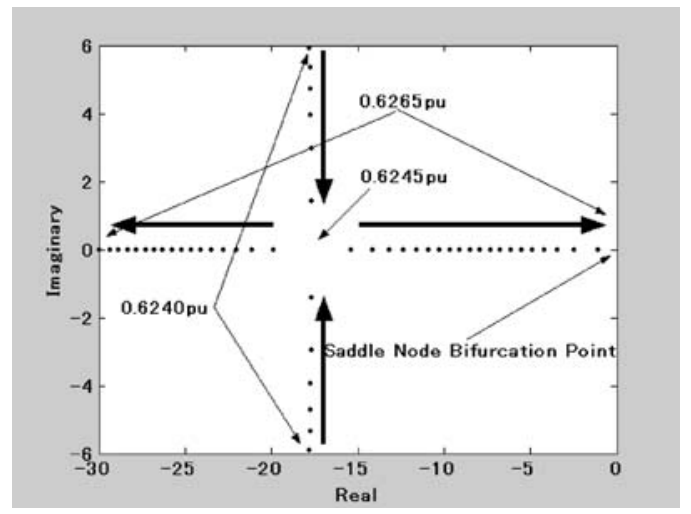

(a) The locus of the eigen values before bifurcation

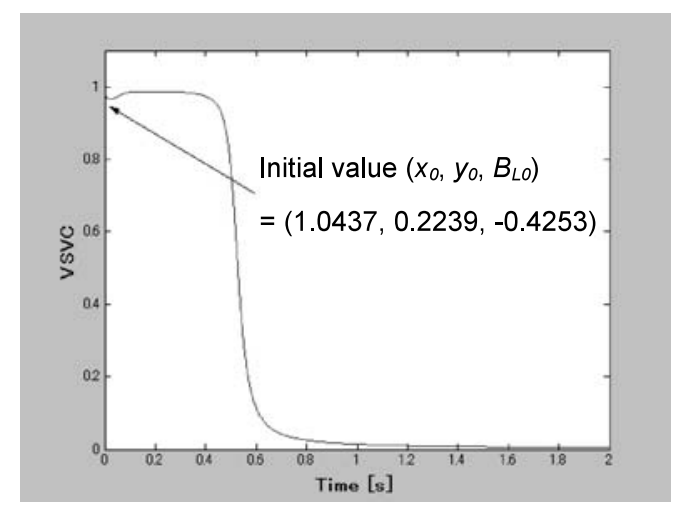

(b) The SVC voltage after bifurcation point

図 5 サドル・ノード分岐点付近の挙動

Fig. 5. Behavior near the saddle node bifurcation point.
の変化範囲は $0.6240 \mathrm{pu}$ から $0.6265 \mathrm{pu}$ である。固有値は $G$ の变化に伴い複素共役の固有値が実数軸方向に移動し，

\section{表 3 各パラメータの標準值}

Table 3. The standard values of the each parameter.

\begin{tabular}{|c|c|}
\hline Parameter & $\begin{array}{l}\text { Standard } \\
\text { value }\end{array}$ \\
\hline Infinite bus voltage $V_{i n f}$ & $1.0 \mathrm{pu}$ \\
\hline Distribution line resistance $1 r_{e 1}$ & $0.1566 \mathrm{pu}$ \\
\hline Distribution line reactance $1 X_{e 1}$ & $0.2625 \mathrm{pu}$ \\
\hline Load conductance $1 G_{1}$ & $0.05 \mathrm{pu}$ \\
\hline Load susceptance $1 B_{1}$ & $0.008 \mathrm{pu}$ \\
\hline Voltage set value of SVC $1 V_{\text {SVCref } 1}$ & $1.0 \mathrm{pu}$ \\
\hline Susceptance of SVC $1 B_{C I}$ & $0.2 \mathrm{pu}$ \\
\hline Slope reactance of SVC $1 k_{1}$ & $0.01 \mathrm{pu}$ \\
\hline PI-controller gain at AVR $1 k_{p 1}$ & 2.1 \\
\hline $\begin{array}{l}\text { Time-lag of first order time constant of } \\
\text { voltage measurement at AVR } 1 T_{m 1}\end{array}$ & $0.03 \mathrm{sec}$ \\
\hline PI-controller time constant at AVR $1 T_{n 1}$ & $0.01 \mathrm{sec}$ \\
\hline Time constant after PI-control at AVR $1 T_{T I}$ & $0.0046 \mathrm{sec}$ \\
\hline Distribution line resistance $2 r_{e 2}$ & $0.2505 \mathrm{pu}$ \\
\hline Distribution line reactance $2 X_{e 2}$ & $0.4201 \mathrm{pu}$ \\
\hline Load conductance $2 G_{2}$ & $0.314 \mathrm{pu}$ \\
\hline Load susceptance $2 B_{2}$ & $-0.08 \mathrm{pu}$ \\
\hline Voltage set value of SVC $2 V_{\text {SVCref } 2}$ & $1.0 \mathrm{pu}$ \\
\hline Susceptance of SVC $2 B_{C 2}$ & $0.2 \mathrm{pu}$ \\
\hline Slope reactance of SVC $2 k_{2}$ & $0.01 \mathrm{pu}$ \\
\hline PI-controller gain at AVR $2 k_{p 2}$ & 2.1 \\
\hline $\begin{array}{l}\text { Time-lag of first order time constant of } \\
\text { voltage measurement at AVR } 2 T_{m 2}\end{array}$ & $0.03 \mathrm{sec}$ \\
\hline PI-controller time constant at AVR $2 T_{n 2}$ & $0.01 \mathrm{sec}$ \\
\hline Time constant after PI-control at AVR $2 T_{T 2}$ & $0.0046 \mathrm{pu}$ \\
\hline
\end{tabular}

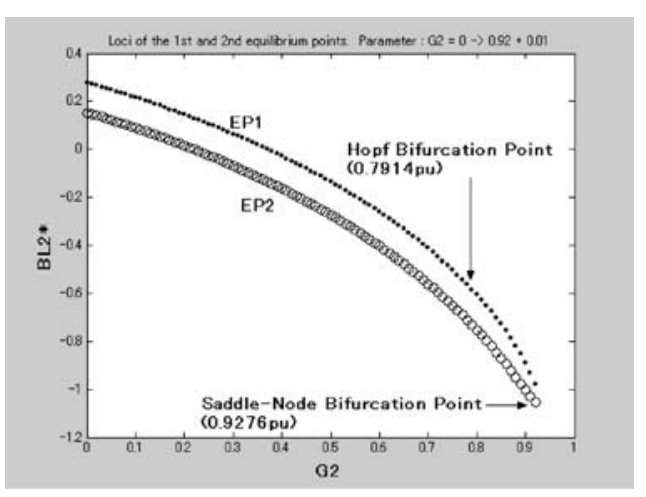

(a) Bifurcation

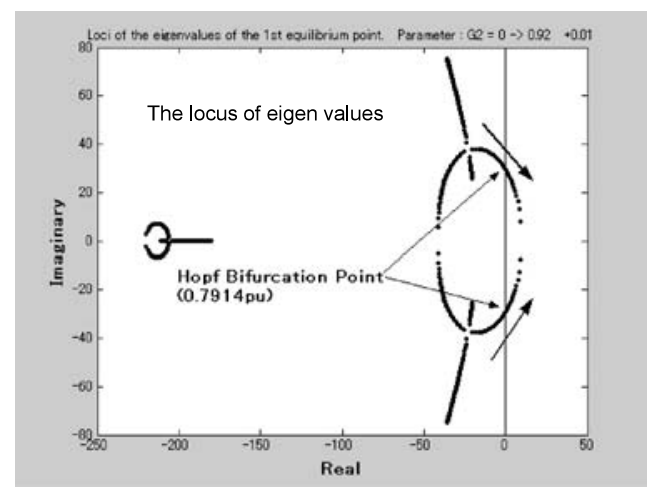

(b) The locus of the eigen values

図 6 分岐図と固有值軌跡

Fig. 6. Bifurcation and the locus of the eigen values. 
$0.6245 \mathrm{pu}$ で $2 つ$ 実数固有値となった後, 1 つは原点方向 に，1 つは負の方向に実数軸上を移動する。固有値の 1 つ が実数軸上を原点方向に移動する樣子は, サドル・ノード 分岐点直前の固有值の特徵的な動きである( () 。図 5(b) に分 岐点通過後 $(G=0.63 \mathrm{pu})$ の実効值モデルによる時間軸シ ミュレーション結果を示す。SVC 電圧 $V_{S V C}$ が非振動的 (7)

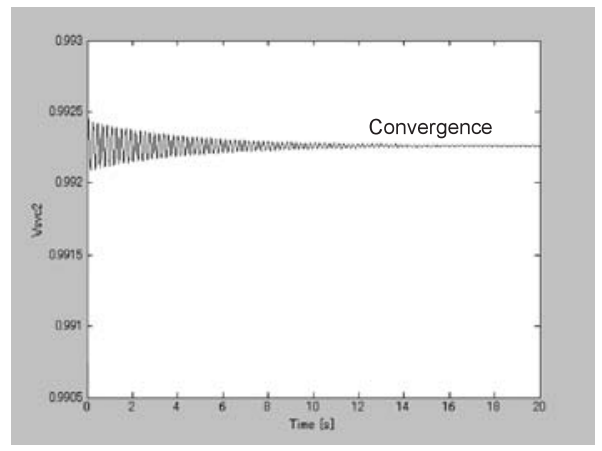

(a) Before Hopf bifurcation point $\left(G_{2}=0.7884 \mathrm{pu}\right)$

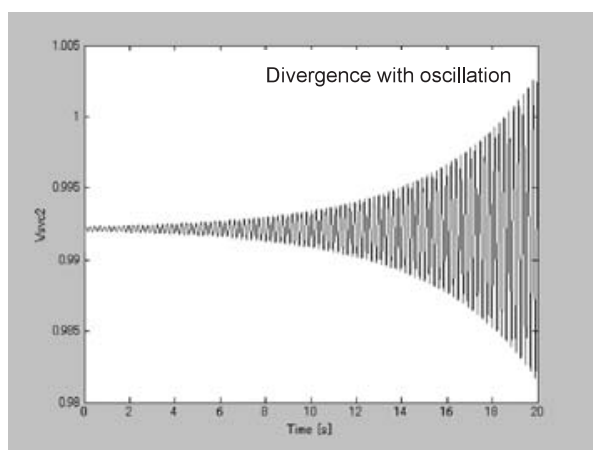

(b) After Hopf Bifurcation point $\left(G_{2}=0.7945 \mathrm{pu}\right)$

图 $7 \mathrm{SVC}$ 電圧

Fig. 7. The SVC voltage.

表 4 各パラメータのサドル・ノード分岐点

Table 4. The saddle node bifurcation points of the each parameter.

\begin{tabular}{|c|c|c|}
\hline Parameter & $\begin{array}{c}\text { Bifurcation } \\
\text { point }\end{array}$ & Unstable domain \\
\hline $\begin{array}{c}\text { Voltage set value of } \\
\text { SVC } 1 V_{\text {SVCrefl }}\end{array}$ & $\begin{array}{l}0.6492 \mathrm{pu} \\
1.6896 \mathrm{pu}\end{array}$ & $\begin{array}{l}V_{\text {SVCref } 1}<0.6492 \mathrm{pu} \\
1.6896 \mathrm{pu}<V_{\text {SVCref } 1}\end{array}$ \\
\hline $\begin{array}{l}\text { Distribution line resis- } \\
\text { tance } 1 r_{e 1}\end{array}$ & $0.3780 \mathrm{pu}$ & $0.3780 \mathrm{pu}<r_{e 1}$ \\
\hline $\begin{array}{r}\text { Distribution line } \\
\text { reactance } 1 X_{e 1}\end{array}$ & $0.0519 \mathrm{pu}$ & $X_{e I}<0.0519 \mathrm{pu}$ \\
\hline Load conductance $1 G_{1}$ & $1.3032 \mathrm{pu}$ & $1.3032 \mathrm{pu}<G_{1}$ \\
\hline $\begin{array}{c}\text { Voltage set value of } \\
\text { SVC } 2 V_{S V C r e f 2}\end{array}$ & $1.4272 \mathrm{pu}$ & $1.4272 \mathrm{pu}<V_{S V C r e f 2}$ \\
\hline $\begin{array}{l}\text { Distribution line resis- } \\
\text { tance } 2 r_{e 2}\end{array}$ & $0.5424 \mathrm{pu}$ & $0.5424 \mathrm{pu}<r_{e 2}$ \\
\hline $\begin{array}{l}\text { Distribution line } \\
\text { reactance } 2 X_{e 2} \\
\end{array}$ & $0.0967 \mathrm{pu}$ & $X_{e 2}<0.0967 \mathrm{pu}$ \\
\hline Load conductance $2 G_{2}$ & $0.9276 \mathrm{pu}$ & $0.9276 \mathrm{pu}<G_{2}$ \\
\hline Infinite bus voltage $V_{i n f}$ & $0.6269 \mathrm{pu}$ & $V_{\text {inf }}<0.6269 \mathrm{pu}$ \\
\hline $\begin{array}{c}\text { Length of distribution } \\
\text { line } 1 \mathrm{mlt} 1\end{array}$ & $\begin{array}{c}3.9742 \\
\text { times }\end{array}$ & 3.9742 times $<$ mlt 1 \\
\hline $\begin{array}{c}\text { Length of distribution } \\
\text { line } 2 \mathrm{mlt} 2\end{array}$ & $\begin{array}{l}3.1737 \\
\text { times }\end{array}$ & 3.1737 times $<$ mlt 2 \\
\hline
\end{tabular}

に崩壊している樣子がわかる。以上より $G=0.6265 \mathrm{pu}$ 近 傍にサドル・ノード分岐点, すなわち SVC の安定限界点が ある。

次にホップ分岐 ${ }^{(5)} に$ 注目し，パラメータ変化による固有 值軌跡の計算を行ったが, 現実的な範囲において, 注目す べき現象は確認されなかった。

〈4 2〉 2 機 SVC を含む系統 表 3 の定数を標準定 数として検討を行った。AVR の PI 制御後のゲイン $k_{01}=$ $1.0, k_{02}=1.0$ とする。配電線 1 はリアクタンス換算で約 $2.99 \mathrm{~km}$ ，配電線 2 は約 $4.79 \mathrm{~km}$ に相当する。

〈4・1〉節と同樣に,(17)式により,パラメータ変化による固 有值軌跡の計算を行った。一例として系統負荷コンダクタン ス $2\left(G_{2}\right)$ をパラメータとした場合の平衡点 $\left(B_{L 2}^{*}\right)$ の分岐図 を図 6(a) , 平衡点 1 (EP1) の固有值軌跡を図 6(b) に示す。

\section{表 5 各パラメータのホップ分岐点}

Table 5. The Hopf bifurcation points of the each parameter.

\begin{tabular}{|c|c|c|}
\hline Parameter & $\begin{array}{c}\text { Bifurcation } \\
\text { point }\end{array}$ & Unstable domain \\
\hline Load conductance $2 G_{2}$ & $0.7914 \mathrm{pu}$ & $0.7914 \mathrm{pu}<G_{2}$ \\
\hline $\begin{array}{c}\text { Voltage set value of } \\
\text { SVC } 2 V_{\text {SVCre/2 }}\end{array}$ & $1.310 \mathrm{pu}$ & $1.310 \mathrm{pu}<V_{\text {SVCref } 2}$ \\
\hline $\begin{array}{c}\text { PI-controller gain at AVR 1 } \\
T_{n 1}\end{array}$ & $0.0012 \mathrm{sec}$ & $T_{n 1}<0.0012 \mathrm{sec}$ \\
\hline $\begin{array}{c}\text { PI-controller gain at AVR 2 } \\
T_{n 2}\end{array}$ & $0.002 \mathrm{sec}$ & $T_{n 2}<0.002 \mathrm{sec}$ \\
\hline $\begin{array}{c}\text { Length of distribution } \\
\text { line } 1 \text { mlt1 }\end{array}$ & $\begin{array}{c}3.8437 \\
\text { times }\end{array}$ & $\begin{array}{c}3.8437 \text { times }< \\
\text { mlt1 }\end{array}$ \\
\hline $\begin{array}{c}\text { Length of distribution } \\
\text { line } 2 \text { mlt2 }\end{array}$ & $\begin{array}{c}3.0227 \\
\text { times }\end{array}$ & $\begin{array}{c}3.0227 \text { times }< \\
\text { mlt2 }\end{array}$ \\
\hline
\end{tabular}

ここで, mlt1, mlt2 は標準配電線インピーダンスからの倍率 を表す。

\section{表 6 各パラメータの標準值}

Table 6. The standard values of the each parameter.

\begin{tabular}{|c|c|}
\hline Parameter & $\begin{array}{c}\text { Standard } \\
\text { value }\end{array}$ \\
\hline Infinite bus voltage $V_{\text {inf }}$ & $1.0 \mathrm{pu}$ \\
\hline Distribution line resistance $1 r_{e 1}$ & $0.1566 \mathrm{pu}$ \\
\hline Distribution line reactance $1 X_{e 2}$ & $0.2625 \mathrm{pu}$ \\
\hline Load conductance $1 G_{1}$ & $0.05 \mathrm{pu}$ \\
\hline Load susceptance $1 B_{1}$ & $0.008 \mathrm{pu}$ \\
\hline Voltage set value of SVC $V_{S V C r e f}$ & $1.0 \mathrm{pu}$ \\
\hline Susceptance of SVC $B_{C}$ & $0.4 \mathrm{pu}$ \\
\hline Slope reactance of SVC $k$ & $0.01 \mathrm{pu}$ \\
\hline PI-controller gain at AVR $k_{p}$ & 2.1 \\
\hline Time-lag of first order time constant of & $0.03 \mathrm{sec}$ \\
\hline voltage measurement at AVR $T_{m}$ & \\
\hline PI-controller time constant at AVR $T_{n}$ & $0.01 \mathrm{sec}$ \\
\hline Time constant after PI-control at AVR $T_{T}$ & $0.0046 \mathrm{sec}$ \\
\hline Distribution line resistance $2 r_{e 2}$ & $0.2505 \mathrm{pu}$ \\
\hline Distribution line reactance $2 X_{e 2}$ & $0.4201 \mathrm{pu}$ \\
\hline Load conductance $2 G_{2}$ & $0.314 \mathrm{pu}$ \\
\hline Load susceptance $2 B_{2}$ & $-0.08 \mathrm{pu}$ \\
\hline Voltage set value of SVR $V_{S V R r e f}$ & $1.0 \mathrm{pu}$ \\
\hline Time constant of SVR $T_{s}$ & $60 \mathrm{sec}$ \\
\hline
\end{tabular}




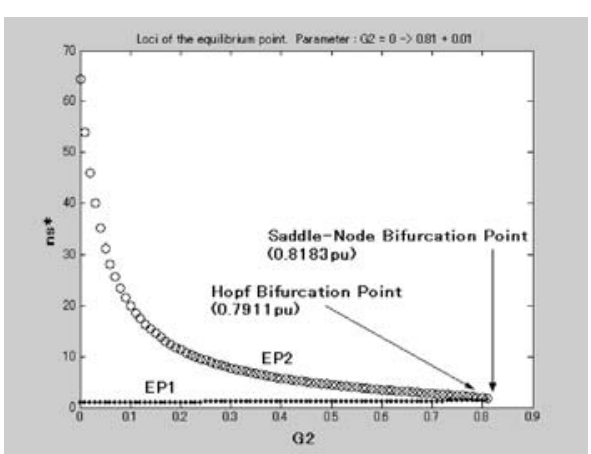

(a) Bifurcation $G_{2}$ vs. $n^{*}$

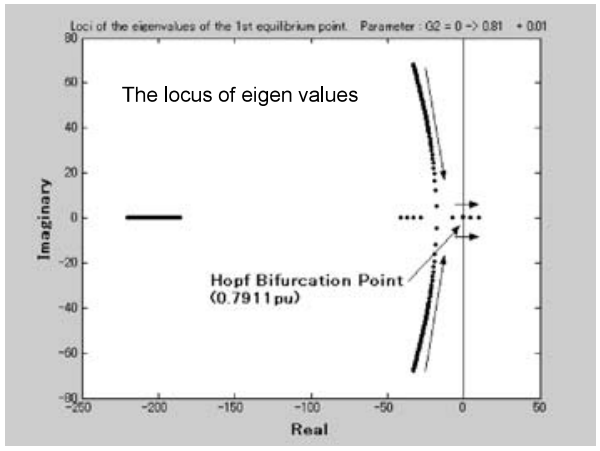

(b) The locus of the eigen values

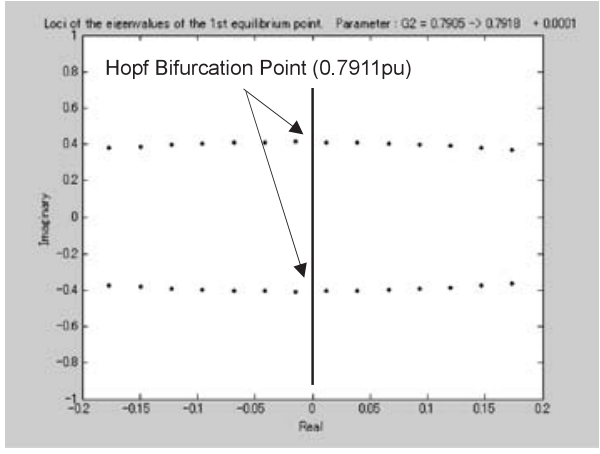

(c) The enlargement of Fig. 8(b)

図 8 分岐図と固有値軌跡

Fig. 8. Bifurcation and the locus of the eigen values.

固有値は $G_{2}$ の変化に伴い複素共役の固有値が $0.7914 \mathrm{pu}$

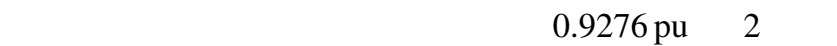
平衡点が衝突 (サドル・ノード分岐点)，光の後消滅する。 図 7(a)，(b) にホップ分岐点通過前 $\left(G_{2}=0.7884 \mathrm{pu}\right)$ と 後 $\left(G_{2}=0.7945 \mathrm{pu}\right)$ の実効值モデルによる SVC2 電圧 $\left(V_{S V C 2}\right)$ を示す。ホップ分岐点通過後 $V_{S V C 2}$ は振動的に発 散しており， $G_{2}=0.7914 \mathrm{pu}$ に分岐点すなわち系の安定動 作限界点がある。

同樣の検討を行い次の表 4 , 表 5 のパラメータにおいて も安定動作限界点 (サドル・ノード分岐点もしくはホップ 分岐点) を確認した。ただし，配電線の亘長を除いては，現 実的ではない值であり，問題ないと考える。

〈4 3〉SVCとSVRを含む系統 表 6 の定数を標準定 数として検討を行った。AVRのPI制御後のゲイン $k_{0}=1.0$

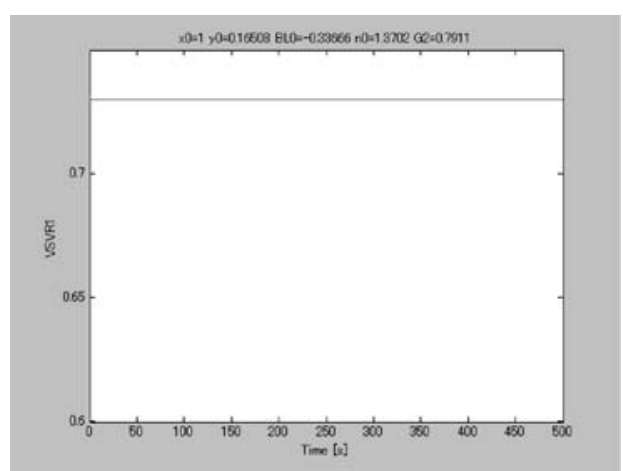

(a) The SVC voltage before bifurcation point (stability)

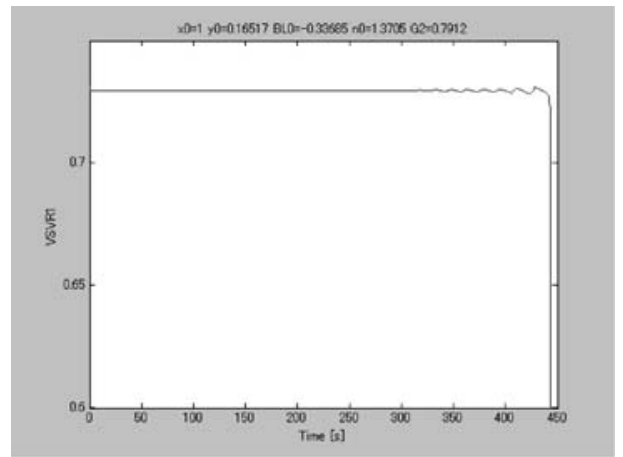

(b) The SVC voltage after bifurcation point (voltage collapses accompanied by vibration)

図 9 SVC 電圧

Fig. 9. The SVC voltage.

表 7 各パラメータのサドル・ノード分岐点 Table 7. The saddle node bifurcation points of the each parameter.

\begin{tabular}{|c|c|c|}
\hline Parameter & $\begin{array}{c}\text { Bifurcation } \\
\text { point }\end{array}$ & Unstable domain \\
\hline Infinite bus voltage $V_{\text {inf }}$ & $0.5537 \mathrm{pu}$ & $V_{\text {inf }}<0.5537 \mathrm{pu}$ \\
\hline $\begin{array}{c}\text { Length of distribution } \\
\text { line } 1 \mathrm{mlt1}\end{array}$ & $\begin{array}{c}3.2615 \\
\text { times }\end{array}$ & 3.2615 times $<$ mlt1 \\
\hline Load conductance $1 G_{1}$ & $0.8124 \mathrm{pu}$ & $0.8124 \mathrm{pu}<G_{1}$ \\
\hline Load susceptance $1 B_{1}$ & $0.8763 \mathrm{pu}$ & $0.8763 \mathrm{pu}<B_{1}$ \\
\hline Length of distribution & $\begin{array}{c}3.2071 \\
\text { times }\end{array}$ & 3.2071 times $<$ mlt2 \\
\hline line 2 mlt2 & $0.8184 \mathrm{pu}$ & $0.8184 \mathrm{pu}<B_{2}$ \\
\hline Load susceptance $2 B_{2}$ & $\begin{array}{c}0.6130 \mathrm{pu} \\
1.4173 \mathrm{pu}\end{array}$ & $\begin{array}{c}V_{\text {SVCref }}<0.6130 \mathrm{pu} \\
1.4173 \mathrm{pu}<V_{\text {SVCref }}\end{array}$ \\
\hline $\begin{array}{c}V_{\text {SVCref }} \\
\text { Voltage set value of SVR } \\
V_{\text {SVRref }}\end{array}$ & $\begin{array}{c}0.6546 \mathrm{pu} \\
1.2937 \mathrm{pu}\end{array}$ & $\begin{array}{c}V_{\text {SVRref }}<0.6546 \mathrm{pu} \\
1.2937 \mathrm{pu}<V_{\text {SVRref }}\end{array}$ \\
\hline
\end{tabular}

とする。配電線 1 はリアクタンス換算で約 $2.99 \mathrm{~km}$, 配電 線 2 は約 $4.79 \mathrm{~km}$ に相当する。

$\langle 4 \cdot 1\rangle$ 節と同樣に, 固有值モデル (18) 式により, パラメー 夕変化に対する固有值軌跡の計算を行った。例として系統 負荷コンダクタンス $2\left(G_{2}\right)$ をパラメータとした場合 $\left(G_{2}\right.$ 以外は標準定数) の平衡点 $\left(n^{*}\right)$ の分岐图を図 8(a), 平衡点 1 (EP1) の固有値軌跡を図 8(b) に示す。図より固有值は $G_{2}$ の変化に伴い複素共役の固有值が $0.7911 \mathrm{pu}$ で虚数軸を 
表 8 各パラメータのホップ分岐点

Table 8. The Hopf bifurcation points of the each parameter.

\begin{tabular}{|c|c|c|}
\hline Parameter & $\begin{array}{c}\text { Bifurcation } \\
\text { point }\end{array}$ & Unstable domain \\
\hline $\begin{array}{c}\text { Length of distribution } \\
\text { line } 2 \text { mlt2 }\end{array}$ & $\begin{array}{c}3.1092 \\
\text { times }\end{array}$ & 3.1092 times $<$ mlt2 \\
\hline Load conductance $2 G_{2}$ & $0.7912 \mathrm{pu}$ & $0.7912 \mathrm{pu}<G_{2}$ \\
\hline $\begin{array}{c}\text { Voltage set value of } \\
\text { SVC } V_{\text {SVCref }}\end{array}$ & $1.3482 \mathrm{pu}$ & $1.3482 \mathrm{pu}<V_{\text {SVCref }}$ \\
\hline $\begin{array}{c}\text { PI-controller time con- } \\
\text { stant at AVR } T_{n}\end{array}$ & $0.0021 \mathrm{sec}$ & $T_{n}<0.0021 \mathrm{sec}$ \\
\hline $\begin{array}{c}\text { Voltage set value of } \\
\text { SVR } V_{\text {SVRref }}\end{array}$ & $0.6862 \mathrm{pu}$ & $V_{\text {SVRref }}<0.6862 \mathrm{pu}$ \\
\hline
\end{tabular}

ここで, $m l t 1, m l t 2$ は標準配電線インピーダンスからの倍率を 表す。また，本検討では $r_{e 1}, X_{e 1}, r_{e 2}, X_{e 2}$ を単独のパラメータ として扱わず，亘長の変化に伴い, $r_{e}$ と $X_{e}$ の比率を保ったま ま変化させることとしたため, $r_{e 1}, X_{e 1}, r_{e 2}, X_{e 2}$ のパラメータ の分岐点は求めていない。

横切り (ホップ分岐点) , $0.8183 \mathrm{pu} て ゙ 2 つ の$ 平衡点が衝突 (サドル・ノード分岐点), 弚の後消滅することがわかる。

図 9(a)，(b)に $G_{2}$ をパラメータとした場合のホップ分岐 点通過前 $\left(G_{2}=0.7911 \mathrm{pu}\right)$ と後 $\left(G_{2}=0.7912 \mathrm{pu}\right)$ の実効值 モデルによる SVR 一次電圧 $\left(V_{S V R 1}\right)$ を示す。ホップ分岐点 通過後 $V_{S V R 1}$ は振動を伴い崩壞しており, $G_{2}=0.7911 \mathrm{pu}$ に 分岐点 , すなわち系の安定動作限界点があることがわかる。

同樣の検討を行い次の表 7 , 表 8 のパラメータにおいて も安定動作限界点 (ホップ分岐点もしくはサドル・ノード 分岐点)を確認した。ただし,配電線の亘長を除いては,現 実的ではない值であり，問題ないと考える。

\section{5. 配電線負荷量による分岐点の変化}

前章まででは，単一のパラメータを，他のパラメータを 固定としたまま, 個別に変化させ, 不安定となる限界值を 調へた。弚の中で, 無限大母線電圧, 配電線亘長, 系統負 荷量, SVC 電圧設定値, SVC の PI 制御系の時定数等に限 界があることがわかった。

しかしながら，負荷量というパラメータは,他のパラメー タと異なり，時々刻々変化するものであるので，負荷量を 変えた条件における他のパラメータの分㞳点について検討 する必要がある。

乥こで, 負荷量を変えた条件で各パラメータの分岐点を 解析したが, 配電線亘長以外のパラメータは負荷量の違い による分岐点の変化が小さかった。乥こで, 配電線負荷量 による分岐点の変化について, 配電線亘長との関係をさら に詳細に解析を行った。

〈5. 1〉解析条件 2 機 SVC のモデルを用いて, 系統 負荷力率あるいは $2 つ の$ 系統負荷量の比 (負荷分布に相当) をパラメータとして変化させた。図 3 における $G_{1}: B_{1}$ お よび $G_{2}: B_{2}$ の比率を変更することにより力率を， $G_{1}, B_{1}$ で表される負荷量と $G_{2} ， B_{2}$ で表される負荷量を変更する ことにより SVC1 の前後における負荷量の比を変更させた。

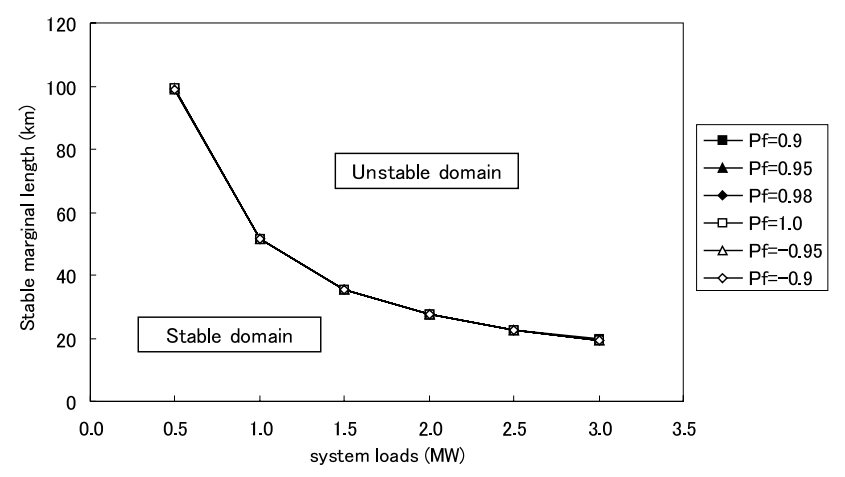

図 10 力率変化による系統負荷量と 安定限界亘長の関係

Fig. 10. Relation between the amount of system loads and stable marginal length by power factor change.

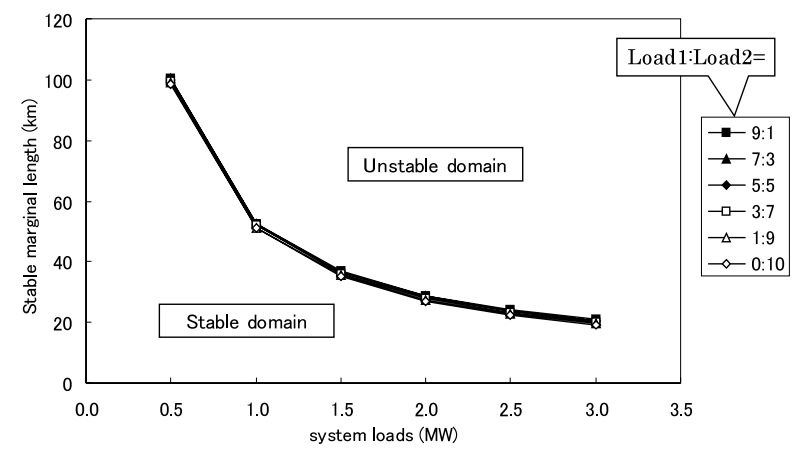

図 11 負荷分布変化による系統負荷量と 安定限界亘長の関係

Fig. 11. Relation between the amount of system loads and stable marginal length by load distribution change.

変更させた範囲は下記の通りである。

・系統負荷力率 進みの 0.9 遅れの 0.9

・系統負荷量の比 $\left(G_{1}: G_{2}\right) \quad 9: 1,7: 3,5: 5,3: 7$, $1: 9,0: 10$

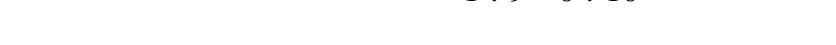
定された条件において， $r_{e 2} ， X_{e 2}$ で表される配電線亘長を 固定したまま, $r_{e 1}, X_{e 1}$ で表される配電線亘長を变化させ， 安定限界となる亘長を求めた。

〈5 2〉解析結果 系統負荷量が大きい場合には安定 限界亘長が短くなり，系統負荷量が小さい場合には安定限 界亘長が長くなる。また, 力率あるいは負荷量の比を変化 させても限界亘長はさほど差異が生じないことが判明した (図 10 , 図 11)。つまり，安定限界亘長の解析における系 統負荷量については, 力率の值ならびに負荷分布を考慮し なくてもよく,配電線全体の系統負荷量だけを考慮すれば よいことがわかった。

また，上記のグラフを両対数平面上で表現すると系統負 荷量と安定限界亘長の関係は直線上に乗るため, 累乗の近 似式で表現できることがわかる (図 12)。このことを利用 すれば，定インピーダンス傾向か強い負荷特性の配電系統 で, 2 機以下の SVC が存在 (設置間隔は $4.79 \mathrm{~km}$ ) するよ 


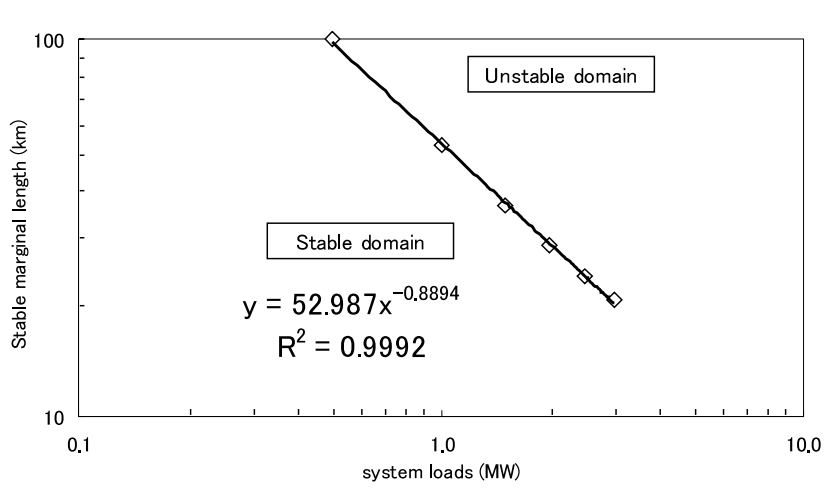

図 12 両対数平面上における系統負荷量と 安定限界亘長の関係

Fig. 12. Relation between the amount of system loads and stable marginal length on a log-log plane.

うな系統においては, SVC の安定性評価か配電線負荷量と 亘長との関係において簡便にできるものと考えられる。し たがって, 分散型電源の系統連系に伴いSVC が導入される ような場合，弚の連系可否判定の目安として使用できる。

\section{6. むすび}

配電系統における単機 SVC, 2 機 SVC の不安定現象, SVC と SVR の相互干渉問題を検討した。

まず単一のパラメータのみを变化させた解析により，以 下のことがわかった。

(1) 系統定数 $\left(G, r_{e}, X_{e}, m l t, V_{i n f}, V_{S V C r e f}\right)$ に関す るパラメータ変化によりサドル・ノード分岐が発生し, 分 岐点通過後 SVC は不安定となるが, 表 2 からもわかるよ うに配電線亘長以外は非現実的な值に分岐点がある。

（2） 2 機SVC およびSVC とSVR の系においても，現 実的なSVC の制御定数の範囲においては, 主に系統定数に 関するパラメータ変化によりサドル・ノード分岐点,ホップ 分岐点か確認され, 分岐点通過後, 系は不安定となる。し たがって，今回対象とした系の安定動作限界点はホップ分 岐点もしくはサドル・ノード分岐点でのみ決定されること がわかった。

次に負荷量を変えた断面での検討を加え，以下のことが わかった。

（1）系統負荷量が大きい配電線の方が不安定となるこ と, 安定限界亘長の解析における系統負荷量については, 力率の值ならびに負荷分布を考慮しなくてもよく，配電線 全体の系統負荷量だけを考慮すればよいことがわかった。 このことを利用すれば，定インピーダンス傾向が強い負荷 特性の配電系統で, 2 機以下の SVC が存在（設置間隔は $4.79 \mathrm{~km})$ するような系統においては, SVC の安定性評価 か配電線負荷量と亘長との関係において簡便にできるもの と考えられる。したがって, 分散型電源の系統連系に伴い SVCか導入されるような場合, 光の連系可否判定の目安と して使用できる。

(平成 16 年 5 月 17 日受付, 平成 16 年 12 月 27 日再受付)

\section{文献}

(1) A.J.P. Ramos and H. Tyll: "Dynamic Performance of a Radial Weak Power Systems with Multiple VAR Compensators", IEEE Trans. Power Syst., Vol.4, pp.1316-1325 (1989-10)

( 2 ) M. Parniani and M.R. Iravani: "Voltage Control Stability and Dynamic Interaction Phenomena of Static VAR Compensators", IEEE Trans. Power Syst., Vol.10, pp.1592-1597 (1995-8)

(3) C.C. Liu and K.T. Vu: "Analysis of Tap-Changer Dynamics and Construction of Voltage Stability Regions", IEEE Trans. Circuits Syst., Vol.36, pp.575-590 (1989-4)

(4) S. Abe, Y. Fukunaga, A. Isono, and B. Kondo: "Power System Voltage Stability”, IEEE Trans. Power App. Syst., Vol.PAS-101, pp.3830-3840 (198210)

( 5 ) S. Sastry: Nonlinear Systems Analysis, Stability, and Control, SpringerVerlag New York, Inc. (1999)

(6) V. Venkatasubramanian, H. Schattler, and J. Zaborszky: "Dynamics of Large Constrained Nonlinear Systems-A Taxonomy Theory", Proc. IEEE, Vol.83, pp.1530-1561 (1995-11)

( 7 ) I. Dobson and H. D. Chiang: "Toward a Theory of Voltage Collapse in Power Systems”, Syst. And Control Lett., Vol.13, pp.253-262 (1989)

清 水 慶 - (正員) 1967 年 1 月 20 日生。1992 年 3 月大阪

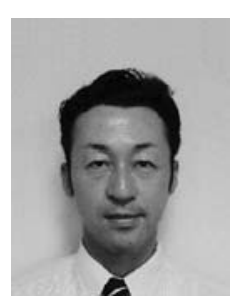
大学基礎工学研究科制御工専攻修了。同年関西電 力 (株) 入社。現在, 同社電力技術研究所電力基 盤技術研究室に勤務。主として, 分散型電源連系 に関する研究に従事。

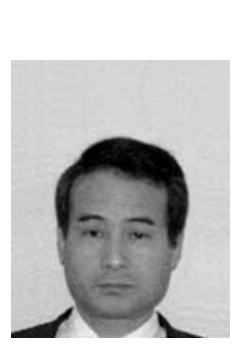

崇 (正員) 1951 年 1 月 30 日生。1975 年 3 月岡山 大学工学研究科修了。同年関西電力 (株) 入社。 現在, 同社電力技術研究所電力基盤技術研究室に 勤務。主として, 分散型電源連系に関する研究に 従事。

中 沢 親 志 (正員) 1968 年 4 月 12 日生。1991 年 3 月慶應義

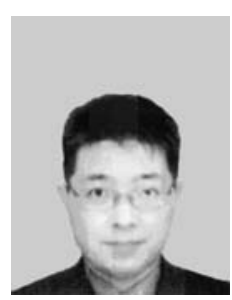
塾大学計測工学科卒業。同年 4 月富士電機 (株) 入社。2000 年〜2002 年, 米国コーネル大学客員研 究員。現在, 富士電機アドバンストテクノロジー (株)。主として, 電力系統の安定性に関する研究 に従事。1999 年電気学術振興賞進歩賞受賞。

中 西要 祐 (正員) 1955 年 1 月 6 日生。1 980 年 3 月早稲田

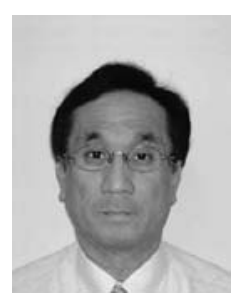
大学大学院理工学研究科修士課程修了。同年 4 月 富士電機 (株) 入社。現在, 富士電機アドバンス トテクノロジー (株)。主として, 電力系統の解 析 , シミュレーション手法および配電系統の運用 制御技術に従事。工学博士。1991 年 IEEE 論文賞 受賞 (PES Education Committee)。IEEE 会員。 